\title{
Index rerum ad Vol. 11
}

\section{ABO blood groups and gastric carcinoma}

363

and genital cancer 29

distribution in Denmark 65, 85

distribution in twins (Sweden) 350

selection model 370

Adrenogenital syndrome, family study 53 Anthropological characters in an isolate

(Hungary) 244

in twins 272

Asia, South and South East, haptoglobins

and transferrins 97 Blood groups and osteogenesis imperfecta

133

see also ABO, Gc, Gm, Haptoglobins,

MNS, Rh and Transferrins

Cancer, gastric, and ABO blood groups 363

in twins 372

genital, and blood groups 29

intestinal, in twins 372

mammary, in twins 372

pulmonary, in twins 372 Ceruloplasmin in monkeys 126 Chromosomal diseases 196

Chronic pyelonephritis and hypertension

58 Congenital malformations of heart,

etiology 289 Consanguineous marriages, fertility 17,

243 Denmark, ABO blood group distribution

65, 85 Dermatoglyphics, family study 162

- $\quad$ in twins (Swedish) 278

Favism, family study 205

Fertility in consanguineous marriages

17, 243 Finger prints, see Dermatoglyphics Gastric cancer and blood groups 363

in twins 372

Gc serum groups, distribution in Sweden

186 Genital cancer and blood groups 29 Global diseases 196 Glucose-6-phosphate

dehydrogenase

activity, family study $205 \mathrm{Gm}$ serum groups, genetics 11

$\mathrm{Gm}(\mathrm{r})$ factor 170

in twins (Swedish) 350

Haemoglobin variants, identification of

abnormal chains 1

identity of abnormal chains 11 
Haptoglobins, distribution in South and

South East Asia 97

in monkeys 126

in twins (Swedish) 350

Heart, congenital malformations, etiology

289 Hungarian isolate study 230 Hypertension and chronic pyelonephritis

58 Inbreeding 230 Infant mortality in consanguineous

marriages 17, 230 Intestinal cancer in twins 372 Isolate studies (Hungary) 230 Lapps,

transferrins 106 Laurence-Moon-Biedl syndrome, family

study 217 Linkage relations of osteogenesis

imperfecta 133 Malformations of the heart, etiology 289 Mammary cancer in twins $372 \mathrm{MN}$

blood groups in twins (Swedish) 350 MNS blood groups, distribution in South

Germany 317 Monkeys, haptoglobins and transferrins

126 Mortality of infants in consanguineous

marriages 17, 230 Osteogenesis imperfecta, linkage relations

133 Ovarial carcinoma and blood groups 29 Phaechromocytoma, family study 137 Pulmonary cancer in twins 372 Pyelonephritis, chronic, and hypertension

$58 \mathrm{Rh}$ blood groups and genital cancer 29

in twins (Swedish) 350

Serum groups, see Gc, Gm, Haptoglobins

and Transferrins Sweden, distribution of Gc groups 186

of transferrins 106

Teeth, pattern of development 154 Toxoplasmosis and congenital malformations of heart 299

Transferrins, distribution in South and

South East Asia 97

380

Index rerum - Index autorum

Transferrins, distribution in Sweden 106

- $\quad$ in monkeys 126

Twins, anthropological characters 272

blood groups 350

cancer 372

dermatoglyphics 278

zygosity diagnosis by polysymptomatic similarity test 251, 265

Twin zygosity diagnosis by serological characters 257

by questionnaires 338

comparison of methods 259, 274, 338

Uterine cancer and blood groups 29 Vaginal cancer and blood groups 29 Zygosity diagnosis, see Twins 